\title{
Synthesis, Characterization, and Flocculation Properties of Branched Cationic Polyacrylamide
}

\author{
Weimin Sun, Guangcheng Zhang, Ling Pan, Helin Li, and Aihua Shi \\ Department of Applied Chemistry, School of Science, Northwestern Polytechnical University, Xian 710072, China \\ Correspondence should be addressed to Weimin Sun; outcast191@163.com
}

Received 7 November 2012; Revised 28 February 2013; Accepted 5 April 2013

Academic Editor: Yulin Deng

Copyright (C) 2013 Weimin Sun et al. This is an open access article distributed under the Creative Commons Attribution License, which permits unrestricted use, distribution, and reproduction in any medium, provided the original work is properly cited.

\begin{abstract}
A water soluble branched cationic polyacrylamide (BCPAM) was synthesized using solution polymerization. The polymerization was initiated using potassium diperiodatocuprate, $\mathrm{K}_{5}\left[\mathrm{Cu}\left(\mathrm{HIO}_{6}\right)_{2}\right](\mathrm{Cu}(\mathrm{III}))$, initiating the self-condensing vinyl copolymerization of acrylamide and acryloxyethyltrimethyl ammonium chloride (DAC) monomer. The resulting copolymer was characterized by the use of Fourier-transform infrared (FTIR) spectroscopy and nuclear magnetic resonance (NMR) spectroscopy. Its flocculation properties were evaluated with standard jar tests of sewage. The effects of initiator concentration, monomer concentration, reaction temperature, and the mass ratio of monomers on intrinsic viscosity and flocculation properties of the product were determined using single-factor experiments and orthogonal experiment.
\end{abstract}

\section{Introduction}

The process of coagulation and flocculation is one of the physicochemical unit processes in water and wastewater treatment $[1,2]$. The object of this process is to turn small particles into larger particles through the use of chemicals called coagulants or flocculants [3]. Flocculants may be inorganic or organic, small molecules or polymers [4]. Based on their ionic nature, polymeric flocculants can be classified as anionic, nonionic, and cationic [5]. Among the polymer flocculants, cationic ones have better flocculating properties [6]. Cationic polymer flocculants have been used widely in wastewater treatment, especially in sludge dewatering [7].

Most of the polymeric flocculants used at present are linear polymers [8]. When the molecular weight increases, the viscosity of the solution increases rapidly, making subsequent synthesis and purification more difficult [9]. A branched polymer has a branched molecular chain point that connects three or more chain segments [10]. Examples are graft copolymers, star-shaped polymers, comb polymers, and dendritic polymers [11]. Compared with linear polymers, branched polymers have lower viscosity and better solubility and can be dispersed more rapidly into water [12].
The synthesis of a branched polyacrylamide using a supernormal valence transition metal, such as potassium diperiodatocuprate $\mathrm{K}_{5}\left[\mathrm{Cu}\left(\mathrm{HIO}_{6}\right)_{2}\right](\mathrm{Cu}(\mathrm{III}))$, as an initiator, in alkaline medium, and being capable of initiating the selfcondensing vinyl polymerization (SCVP) of acrylamide, and then the branched polyacrylamide was obtained [13]. The self-condensing vinyl polymerization of acrylamide has been reported [14], but has not been used as a flocculant.

We previously reported the synthesis of a branched nonionic polyacrylamide (BNPAM) [15]. It demonstrated better flocculation properties for clay suspension, but did not show good flocculation performance for sewage. Now, we developed a novel branched cationic flocculation agent. It was synthesized using acrylamide (AM) and acryloxyethyltrimethyl ammonium chloride (DAC) in a selfcondensing vinyl copolymerization (SCVCP) reaction. The polymerization was initiated using potassium diperiodatocuprate, $\mathrm{K}_{5}\left[\mathrm{Cu}\left(\mathrm{HIO}_{6}\right)_{2}\right](\mathrm{Cu}(\mathrm{III}))$, as the initiator. The branched cationic polyacrylamide product was characterized using Fourier-transform infrared (FTIR) and $1 \mathrm{H}$ nuclear magnetic resonance (1H NMR) spectroscopy. Flocculation properties of polymers obtained were evaluated by the efficiencies of turbidity and chemical oxygen demand (COD) removal in a standard jar test with sewage. 


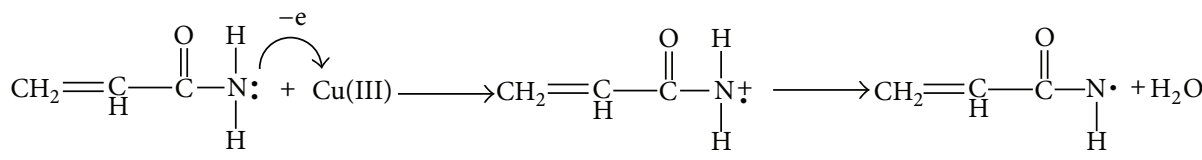<smiles>[M]CC=CC(=O)N[Y19]</smiles>

FIGURE 1: Scheme of initiating process.

\section{Experimental Section}

2.1. Chemicals. Acryloxyethyltrimethyl ammonium chloride (DAC, industrial grade) was provided by the Yantai Spark Group, China. Acrylamide (AM), copper sulphate $\left(\mathrm{CuSO}_{4} \cdot 5 \mathrm{H}_{2} \mathrm{O}\right)$, potassium periodate $\left(\mathrm{KIO}_{4}\right)$, potassium persulfate $\left(\mathrm{K}_{2} \mathrm{~S}_{2} \mathrm{O}_{8}\right)$, potassium hydroxide $(\mathrm{KOH})$, sodium chloride $(\mathrm{NaCl})$, silver nitrate $\left(\mathrm{AgNO}_{3}\right)$, nitric acid $\left(\mathrm{HNO}_{3}\right)$, ceric sulphate $\left(\mathrm{Ce}\left(\mathrm{SO}_{4}\right)_{2} \cdot 4 \mathrm{H}_{2} \mathrm{O}\right)$, ferrous ammonium sulphate $\left(\left(\mathrm{NH}_{4}\right)_{2} \mathrm{Fe}\left(\mathrm{SO}_{4}\right)_{2} \cdot 6 \mathrm{H}_{2} \mathrm{O}\right)$, potassium dichromate $\left(\mathrm{K}_{2} \mathrm{Cr}_{2} \mathrm{O}_{7}\right)$, silver sulfate $\left(\mathrm{Ag}_{2} \mathrm{SO}_{4}\right)$, mercury sulfate $\left(\mathrm{HgSO}_{4}\right)$, acetone, and absolute alcohol were of analytical grade and were purchased from the Tianjin Kemiou Chemical Reagent Co., Ltd., China. Reagents were used as received, without further purification.

2.2. Preparation. Preparation of $\mathrm{Cu}(\mathrm{III})$ solution: copper sulphate $(3.54 \mathrm{~g})$, potassium periodate $(6.80 \mathrm{~g})$, potassium persulfate $(2.20 \mathrm{~g})$, and potassium hydroxide $(9 \mathrm{~g})$ were added to about $250 \mathrm{~mL}$ of water. The mixture was shaken thoroughly and heated on a hot plate. In about $20 \mathrm{~min}$, the boiling mixture turned intensely red, and the boiling was continued for another $20 \mathrm{~min}$ to complete the reaction. The resulting mixture was cooled, filtered through a sintered glass crucible (G-4), and diluted to $250 \mathrm{~mL}$ with double-distilled water [16].

2.3. Synthesis. The branched cationic polyacrylamide was synthesized using AM and DAC in an aqueous solution. The $\mathrm{AM}$ and distilled water were added to a $250 \mathrm{~mL}$ three-necked flask equipped with a stirrer and a thermometer. The solution was bubbled with nitrogen for 30 minutes to remove oxygen. DAC monomer and the $\mathrm{Cu}(\mathrm{III})$ solution as an initiator were added. The final solution was placed in a water bath at a specific reaction temperature for a period of time. At the end of polymerization, the solution was precipitated using acetone and washed with acetone and absolute alcohol several times. The polymer was then dried in a vacuum oven at $50^{\circ} \mathrm{C}$ for $24 \mathrm{~h}$.

2.4. Characterizations. Fourier-transform infrared (FTIR) spectroscopy of the products in $\mathrm{KBr}$ pellets $(2 \mathrm{mg} / 200 \mathrm{mg}$ ) was obtained using a Nicolet IS10 spectrophotometer with a DTGS detector and OMNIC 7.0 software. 128 scans were evaluated at a resolution of $4 \mathrm{~cm}^{-1}$. Viscosity measurements of the polymer solutions were carried out using an Ubbelohde viscometer $(4-0.57)$ at $30^{\circ} \mathrm{C}$. The viscosities were measured in dilute aqueous solution.

NMR measurements were conducted using a Varian INOVA-400 spectrometer at room temperature with $\mathrm{D}_{2} \mathrm{O}$ as the solvent. Turbidity was measured using a Turbidimeter (GDS-3B). Chemical oxygen demand (COD) was measured according to Chinese national standard methods [17]. All polymer solutions were made using double-distilled water. Prior to the measurements, the solutions were allowed to cool at room temperature for $15 \mathrm{~min}$.

Flocculation properties of the branched cationic polyacrylamide were evaluated using jar tests of sewage. The sewage was obtained from the wastewater treatment plant of Chang'an campus, Northwestern Polytechnical University. The quality of sewage has been similar to the traditional municipal wastewater, the initial COD was $400 \mathrm{mg} / \mathrm{L}$, turbidity was $200 \mathrm{NTU}$, and $\mathrm{pH}$ was about $6-8$. The coagulation experiments were carried out using a jar test apparatus with six paddles. Sewage sample was added into $1000 \mathrm{~mL}$ beaker. The experiment was firstly carried out for $1 \mathrm{~min}$ with the paddle speed of $400 \mathrm{rpm}$, followed by the flocculation period for $10 \mathrm{~min}$ with $40 \mathrm{rpm}$. After the sedimentation lasted $15 \mathrm{~min}$, the supernatant sample was withdrawn for turbidity and COD analysis.

\section{Results and Discussion}

3.1. Reaction Mechanism. The reaction mechanism of preparation of branched cationic polyacrylamide was that the acrylamide (AM) and acryloxyethyltrimethyl ammonium chloride (DAC) were initiated by potassium diperiodatocuprate, $\mathrm{K}_{5}\left[\mathrm{Cu}\left(\mathrm{HIO}_{6}\right)_{2}\right](\mathrm{Cu}(\mathrm{III}))$, initiating the self-condensing vinyl copolymerization of AM and DAC monomer. SCVCP of $\mathrm{AB}^{*}$ inimers with conventional monomers is a facile approach to obtain functional branched polymers because different types of functional groups can be incorporated into a polymer, depending on the chemical nature of the comonomer [18]. AM was formed to $\mathrm{AB}^{*}$ inimers in the initiating of $\mathrm{Cu}(\mathrm{III})$, and the initiating process was shown in Figure 1.

When the DAC was added, the free radical formed can initiate the self-condensing vinyl polymerization of AM and DAC, and then the branched cationic polyacrylamide (BCPAM) was formed; the reaction scheme was shown in Figure 2. 
<smiles>C=CC(N)=O</smiles><smiles>C=CC(=O)NC(CC(CC(CC(CCCCC)C(N)=O)C(N)=O)C(=O)OCC[N+](C)(C)C)C(N)=O</smiles>

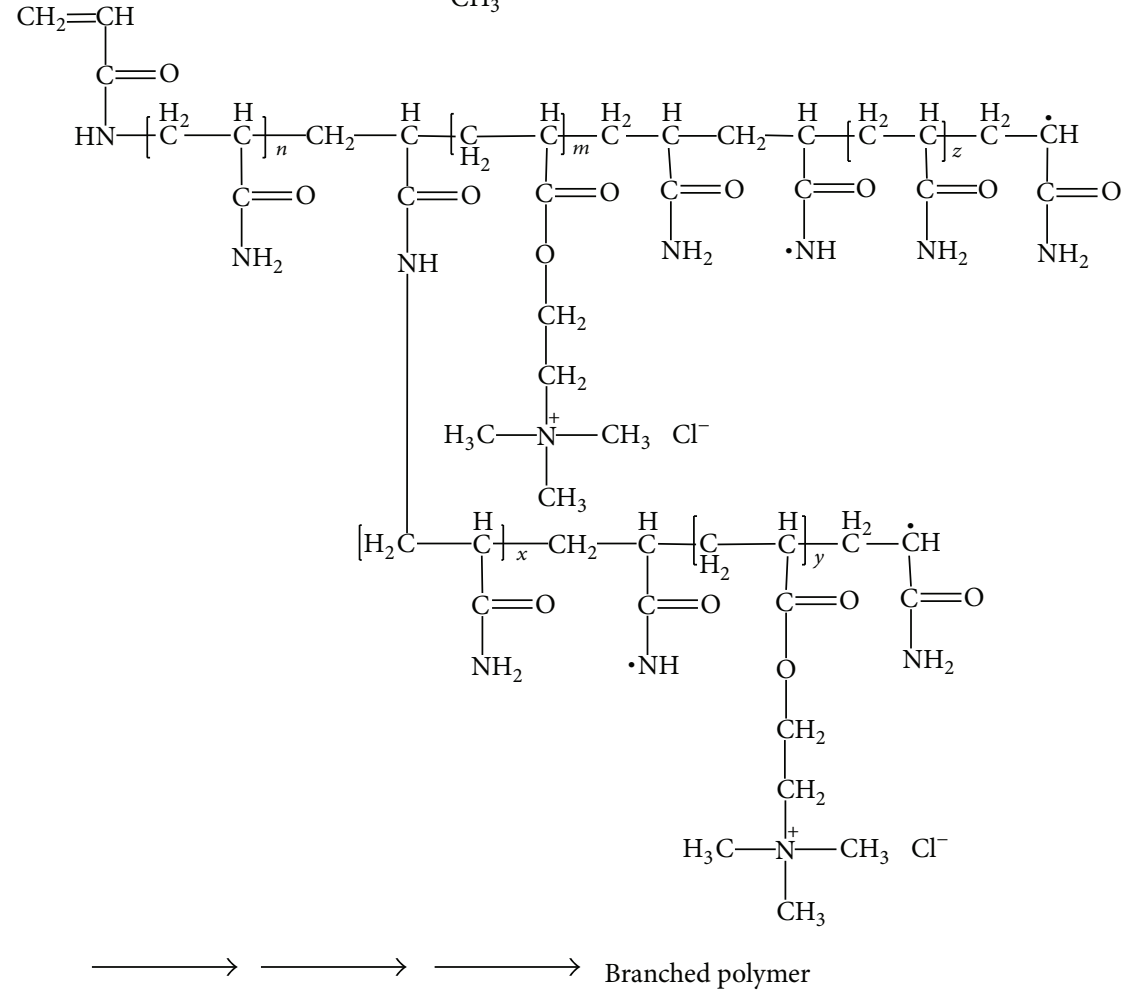

FIGURE 2: Synthesis reaction of branched cationic polyacrylamide.

\subsection{Characterization}

3.2.1. FTIR Spectroscopy. Infrared spectroscopy was performed to determine the structure of the branched cationic polyacrylamide (Figure 3 ). The absorption peak at wavelength $1170 \mathrm{~cm}^{-1}$ was from bending vibration of acyl oxygen groups, $1460 \mathrm{~cm}^{-1}$ was associated with the stretching vibration of acyl amino groups, $1480 \mathrm{~cm}^{-1}$ was assigned to the stretching vibration of methyl groups, $1600 \mathrm{~cm}^{-1}$ was from the bending vibration of imino groups, $1660 \mathrm{~cm}^{-1}$ was associated with the extension vibrating of carbonyl groups in $\mathrm{AM}$, and $2960 \mathrm{~cm}^{-1}$ was associated with the extension vibration of methylene groups.

3.2.2. $1 H$ NMR Spectroscopy. $1 \mathrm{H}$ NMR spectroscopy of the branched cationic polyacrylamide solution in $\mathrm{D}_{2} \mathrm{O}$ is shown in Figure 3.

From Figure 4, it can be seen that chemical shift of $\mathrm{H}$ atoms (1) was $3.183 \mathrm{ppm}, \mathrm{H}$ atoms (2) was $3.716 \mathrm{ppm}, \mathrm{H}$ atoms (3) was $=4.533 \mathrm{ppm} \mathrm{H}$ atoms (4) was $1.805 \mathrm{ppm}, \mathrm{H}$ atoms (5) was $2.338 \mathrm{ppm}$, H atoms (6) was $1.598 \mathrm{ppm}, \mathrm{H}$ atoms (7) was $5.649 \mathrm{ppm}$, and $\mathrm{H}$ atoms (8) was $6.023 \mathrm{ppm}$. 


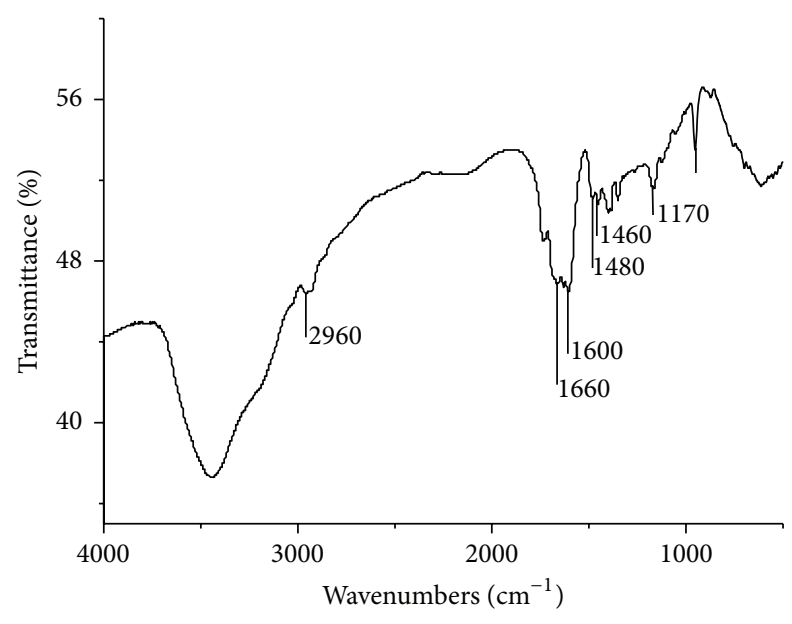

FIGURE 3: FTIR of branched cationic polyacrylamide.

The characteristic absorption peak of $-\mathrm{NH}-$ and $-\mathrm{NH}_{2}$ groups was seen with infrared spectroscopy, and the characteristic chemical shift of $-\mathrm{NH}$ and $-\mathrm{NH}_{2}$ groups was seen using $1 \mathrm{H}$ NMR spectroscopy. The structure of the branched polyacrylamide was the same as initially expected.

3.3. Single-Factor Experiments. In order to investigate the effects of concentration of initiators, concentration of monomers, reaction temperature, ratio of monomers on intrinsic viscosity, and flocculating performance of branched cationic polyacrylamide, a series single-factor experiments were conducted.

3.3.1. Effects of the Concentration of Initiators. Because the concentration of initiators has great influence on the synthesis of branched cationic polyacrylamide, the first step is to determine the optimum concentration of initiator. The reaction temperature was kept at $50^{\circ} \mathrm{C}$ and the reaction time was kept at $2.5 \mathrm{~h}$. The total concentration of monomer was $35 \%$, the ratio of monomer was $1: 1$, while the concentration of $\mathrm{Cu}$ (III) was $4,5,6,7$, and $10 \times 5.6 \times 10^{-4} \mathrm{~mol} \cdot \mathrm{L}^{-1}$, respectively. Results are shown in Figures 5, 6, and 7.

Figure 5 illustrates the effects of concentration of initiators on intrinsic viscosity and rates of production. Figure 5 shows that, with the increasing of concentration of initiators, the rates of production and intrinsic viscosity of branched cationic polyacrylamide increased together. However, if the concentration of initiators was too high, the intrinsic viscosity of branched cationic polyacrylamide decreased. From Figure 5, it can also be seen that the intrinsic viscosity rises to the maximum when the concentration of initiator is $7 \times 5.6 \times$ $10^{-4} \mathrm{~mol} \cdot \mathrm{L}^{-1}$.

Figures 6 and 7 are curves of the flocculation performance branched cationic polymers obtained for sewage under different concentrations of initiators. Figure 7 illustrates the efficiencies of turbidity removal, and Figure 8 demonstrates the efficiencies of COD removal. From Figures 7 and 8, it can be seen that the flocculation properties of copolymer obtained were worse with the lower initiator, and the efficiencies of turbidity and COD removal for sewage were lower too. With the increase of the concentration of initiators, the amount of free radical increased, the probability of chain growth increased at the same time, the molecular chain elongated, the intrinsic viscosity rose, and the flocculation property of copolymer obtained became better. If the concentration of initiators was too much, the free radical generated was too much, the propagation of chain transfer increased, and the molecular chain was shorter. The experimental demonstrated the concentration of initiator at $7 \times 5.6 \times 10^{-4} \mathrm{~mol} / \mathrm{L}$, the intrinsic viscosity of copolymer obtained was the optimum, and the flocculation property was the optimum too. So the concentration of initiator at $7 \times 5.6 \times 10^{-4} \mathrm{~mol} / \mathrm{L}(20 \%$ total concentration of monomers) was the optimum.

3.3.2. Effects of the Concentration of Monomers. In order to investigate the influence of concentration of monomers on intrinsic viscosity and flocculation performance of branched cationic polyacrylamide, the concentration of $\mathrm{Cu}$ (III) was $0.5 \%$ of total monomers, the reaction temperature was kept constant at $50^{\circ} \mathrm{C}$, and the reaction time was kept constant at $2.5 \mathrm{~h}$, while the mass concentration of total monomers was $15 \%, 20 \%, 25 \%, 30 \%, 35 \%$, and $40 \%$, respectively. The results are shown in Figures 8, 9, and 10.

Figure 8 illustrates the relationship between concentration of monomers and the rates of production and intrinsic viscosity of branched cationic polyacrylamide. From Figure 8 , it can be seen that, when the concentration of monomer were lower the concentration of radical and the intrinsic viscosity of polymer were lower too. With the increase of concentration of monomers, the probability of collision between monomer radicals becomes larger, and the intrinsic viscosity of polymer increases. The intrinsic viscosity of polymer was the highest when the concentration of monomer was 35\%; after that, the intrinsic viscosity and rates of production decreased.

Figures 9 and 10 are the curves of the flocculation performance of branched cationic polymers obtained for sewage under different concentrations of monomers. Figure 9 illustrates the efficiencies of turbidity removal, and Figure 10 demonstrates the efficiencies of COD removal. It can be seen, from Figures 9 and 10, that the flocculation properties of copolymer obtained were worse during the lower concentration of monomer, and the efficiencies of turbidity and COD removal for sewage were lower too. With the increases of the concentration of monomers, the amount of free radical increases, the probability of chain growth increases at the same time, the molecular chain elongates, the intrinsic viscosity rises, and the flocculation property of copolymer obtained becomes better. But if the concentration of monomers was too much, the free radical generated was too much, the propagation of chain transfer increased, and the molecular chain became shorter. The experimental demonstrated the concentration of monomers at $35 \%$, the intrinsic viscosity of copolymer obtained was the best, and the flocculation property was the best too. So the mass concentration of monomers at $35 \%$ was the optimum. 


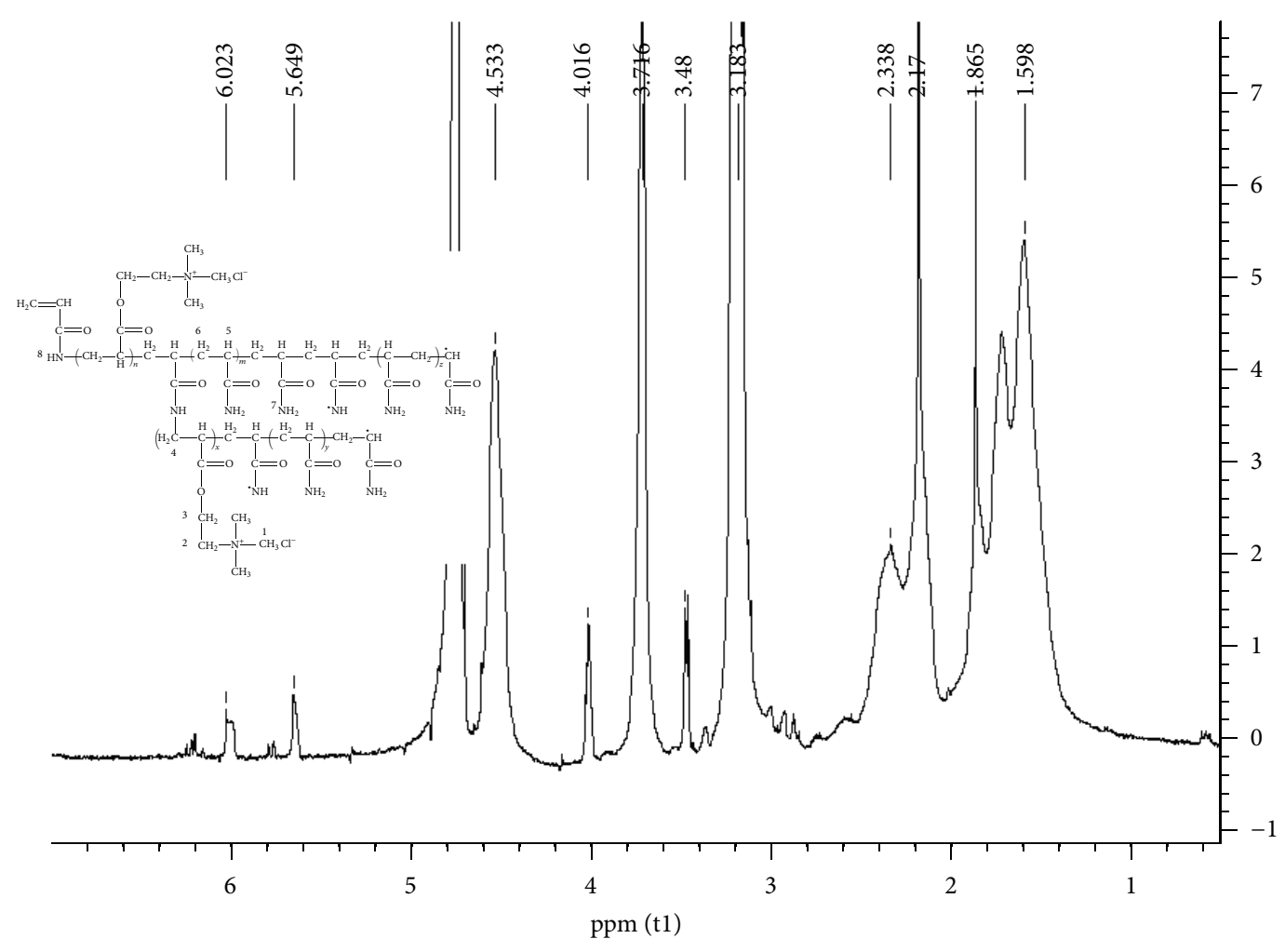

FIGURE 4: 1H NMR of branched cationic polyacrylamide.

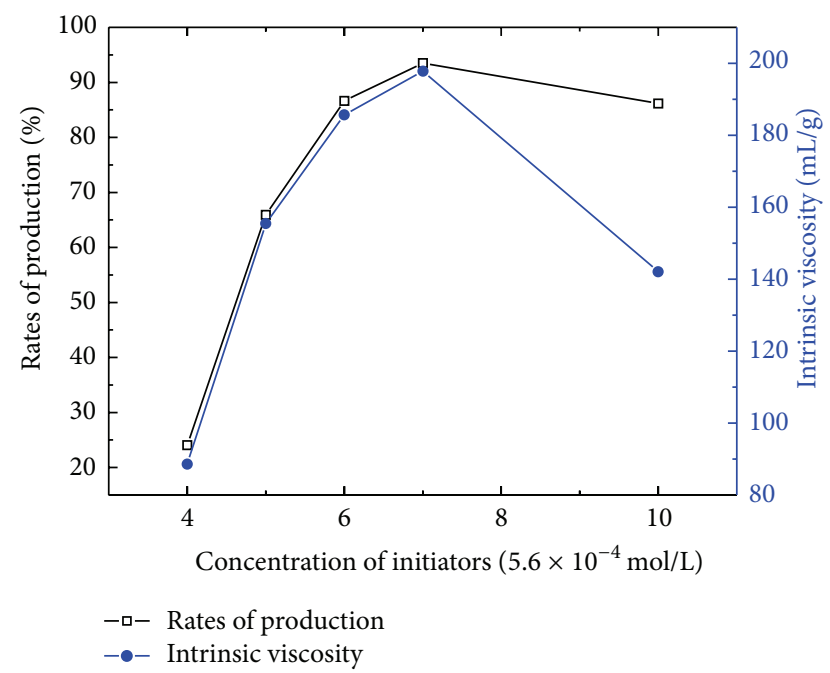

Figure 5: Effects of concentration of initiators on intrinsic viscosity and rates of production.

3.3.3. Effects of Reaction Temperature. In order to study the effect of reaction temperature on intrinsic viscosity and flocculation performance of branched cationic polyacrylamide, the volume of initiator was kept constant at $7 \times 5.6 \times$ $10^{-4} \mathrm{~mol} / \mathrm{L}$ and concentration of monomer was kept constant at $35 \%$, the ratio of monomers was $1: 1$, while the reaction temperature was $35,40,45,50,55$, and $60^{\circ} \mathrm{C}$, respectively. The results are shown in Figures 11, 12, and 13.

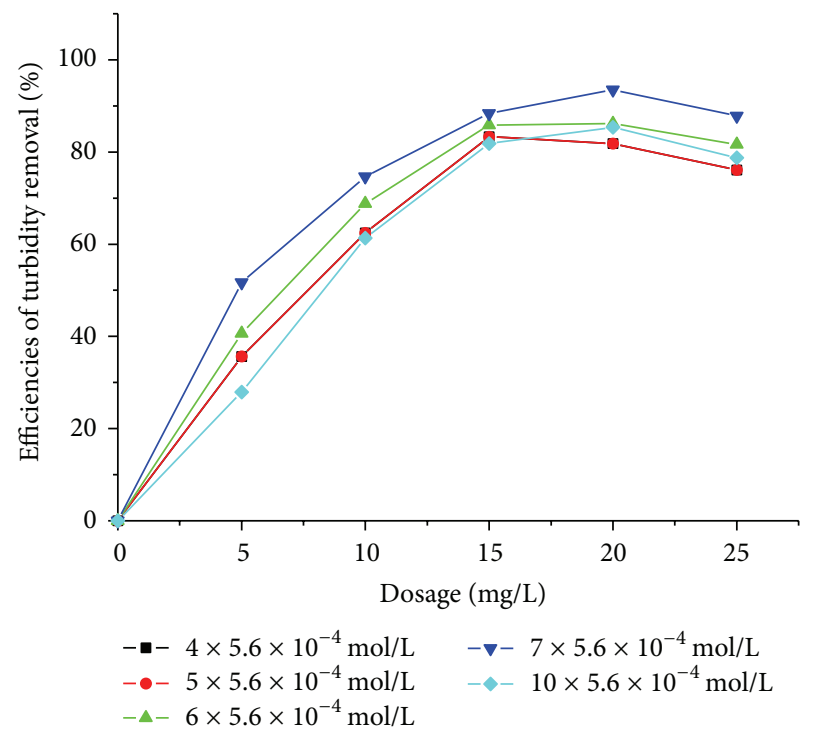

FIGURE 6: Effects of concentration of initiators on turbidity removal for sewage.

Figure 11 illustrates the relationship between reaction temperature and intrinsic viscosity of branched polyacrylamide. From Figure 11, it can be seen that, with the increase of reaction temperature, the intrinsic viscosity decreased. Because the constant of chain transfer and chain termination increased in higher temperature, these accelerated the velocity of polymerization but made its termination in 


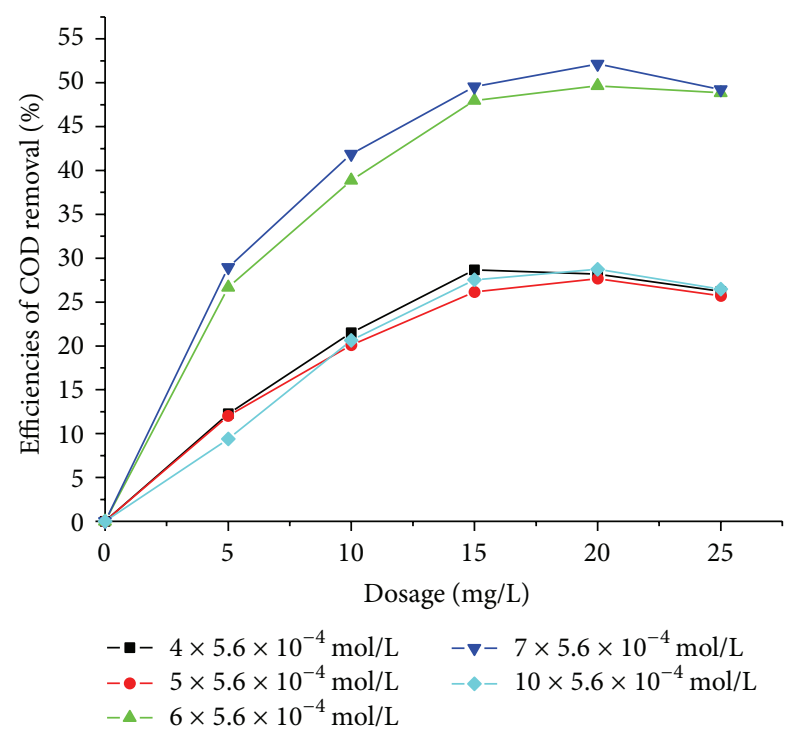

FIGURE 7: Effects of concentration of initiators on COD removal for sewage.

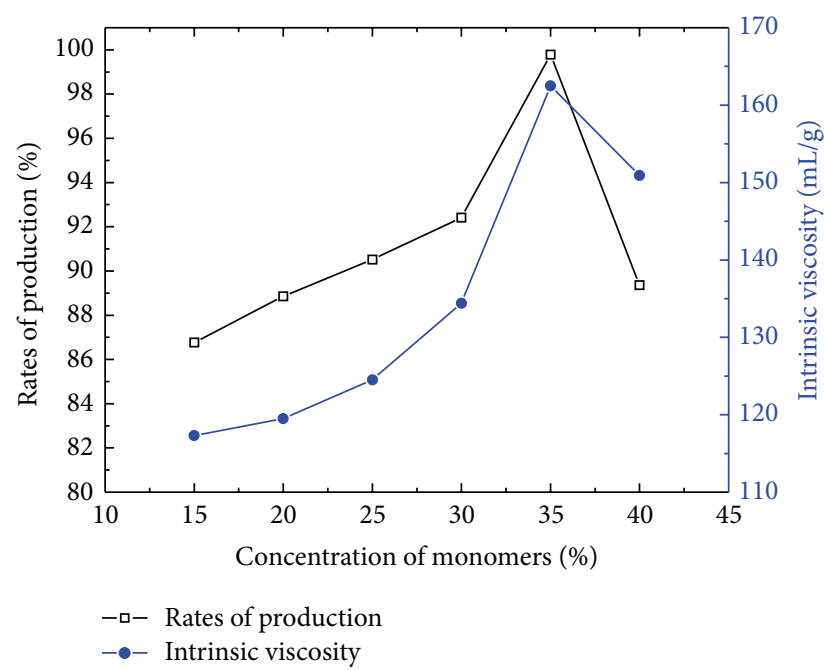

FIGURE 8: Effects of concentration of monomers on intrinsic viscosity and rates of production.

the end, so the intrinsic viscosity of polymers decreased. From Figure 11, it can also be seen that, with the increase of reaction temperature, the rates of production increased at first and decreased in the end. When the temperature was lower, the activity of monomer radical decreased, and the probability of collision between monomer radicals was lower too. With the increase of reaction temperature, and the probability of collision between monomer radicals increased. The rates of production were the highest when the reaction temperature was $45^{\circ} \mathrm{C}$; after that the radical concentration became so high, and the propagation of polymeric reaction was inhibited, so the rates of production decreased.

Figures 12 and 13 were the curves of the flocculation performance branched cationic polymers obtained for sewage under different reaction temperature. Figure 12 illustrateds

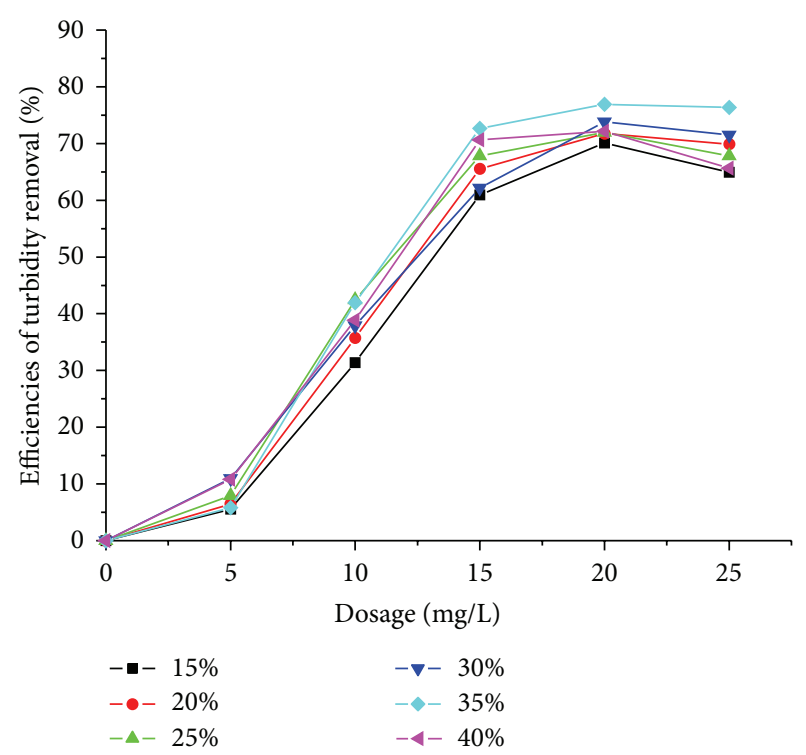

FIGURE 9: Effects of concentration of monomers on turbidity removal for sewage.

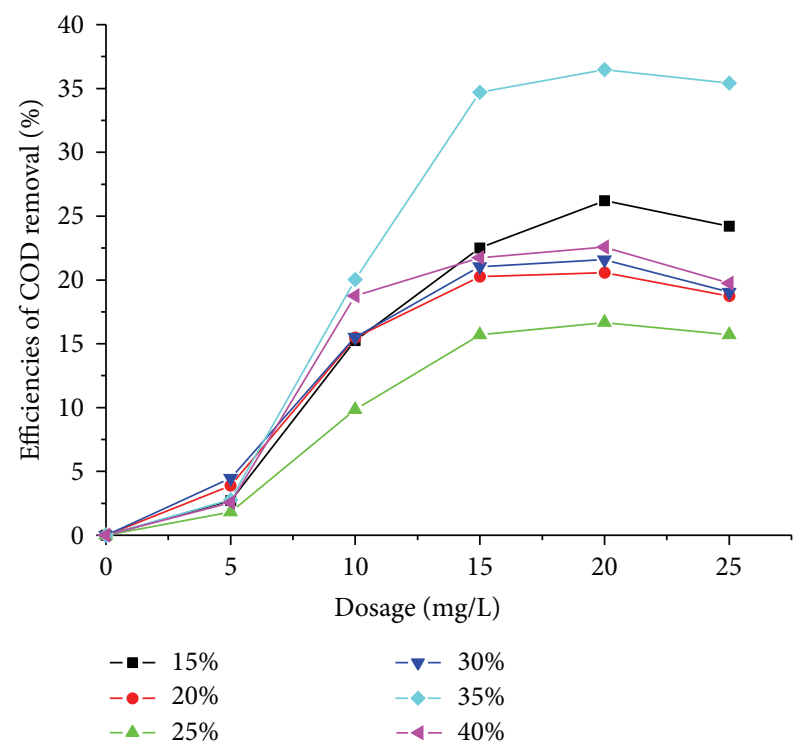

FIGURE 10: Effects of concentration of monomers on COD removal for sewage.

the efficiencies of turbidity removal, and Figure 13 demonstrated the efficiencies of COD removal. It can be seen from Figures 12 and 13 that the flocculation properties of copolymer obtained were worse with the lower reaction temperature, and the rate of turbidity and COD removal for sewage was lower too. With the increase of the reaction temperature, the amount of free radical increased, the probability of chain growth increased at the same time, the molecular chain elongated, intrinsic viscosity became larger, and the flocculation property of copolymer obtained became better too. But if the reaction temperature was too high, the free radical generated was too much, the propagation of chain 


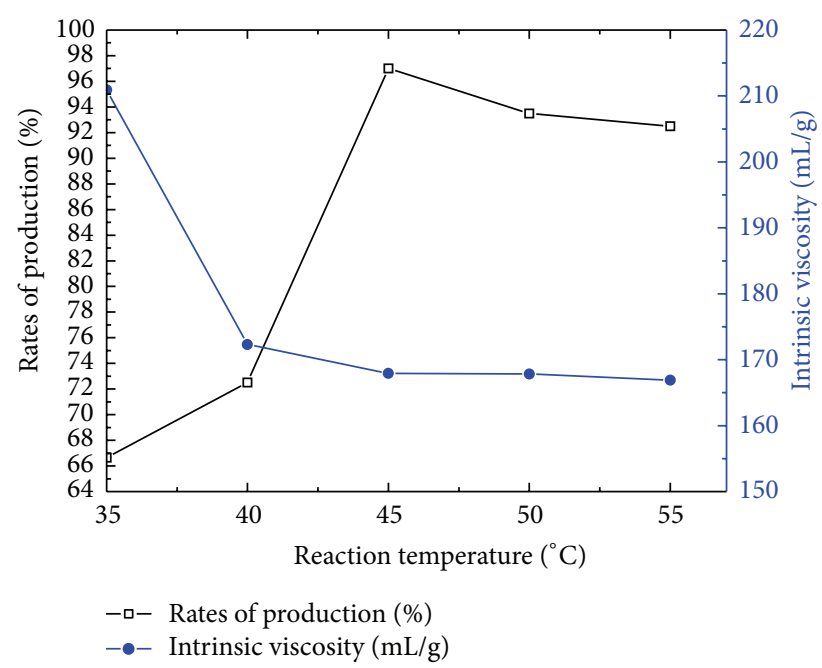

FIGURE 11: Effects of reaction temperature on intrinsic viscosity and rates of production.

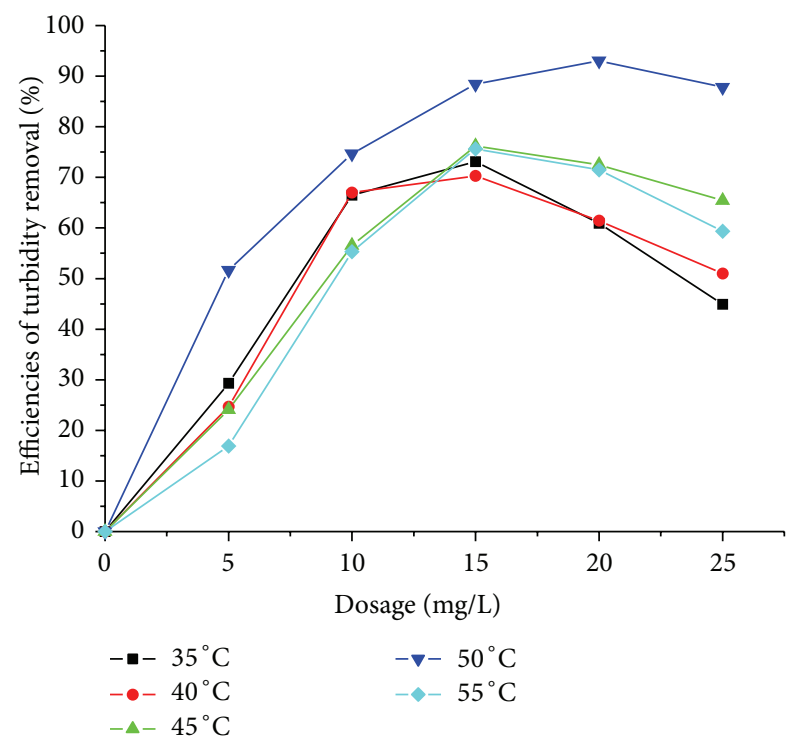

FIGURE 12: Effects of reaction temperature on turbidity removal for sewage.

transfer increased, and the molecular chain became shorter. The experimental demonstrated the reaction temperature at $50^{\circ} \mathrm{C}$, and the flocculation property was the best too. So the reaction temperature at $50^{\circ} \mathrm{C}$ was the optimum.

3.3.4. Effects of the Ratio of $A M$ and DAC. Based on threegroup experiment determined above, the optimum mass concentration of monomers was $35 \%$, and the optimum concentration of initiators was $7 \times 5.6 \times 10^{-4} \mathrm{~mol} / \mathrm{L}$, the optimum reaction temperature was $50^{\circ} \mathrm{C}$. The forth step is to determine the optimum weight ratio of monomers, and the weight ratio of $\mathrm{AM}: \mathrm{DAC}$ is $3: 2,2: 1,1: 1,1: 2$, and $2: 3$, respectively. The results are shown in Figures 14, 15, and 16.

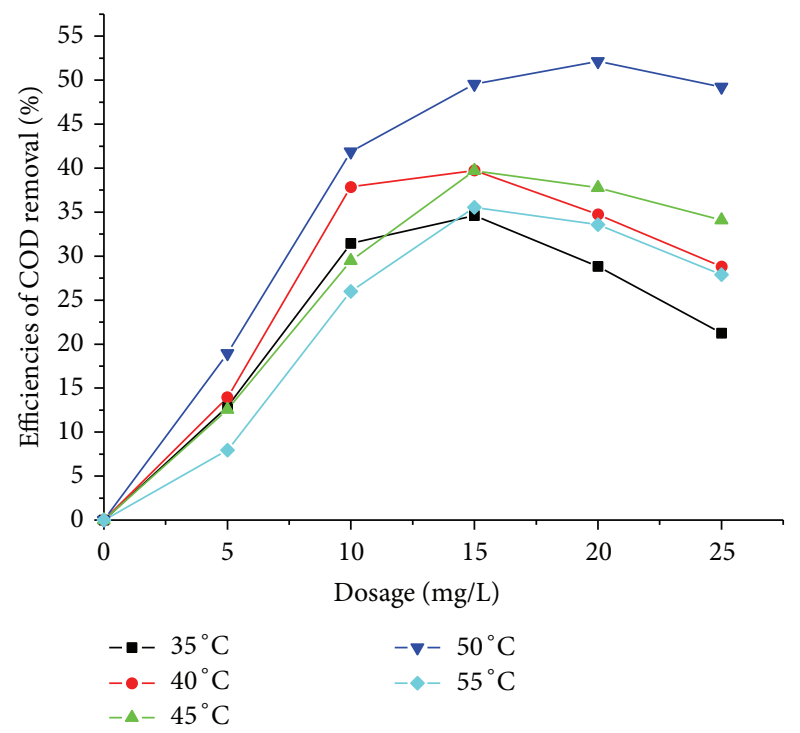

FIGURE 13: Effects of reaction temperature on COD removal for sewage.

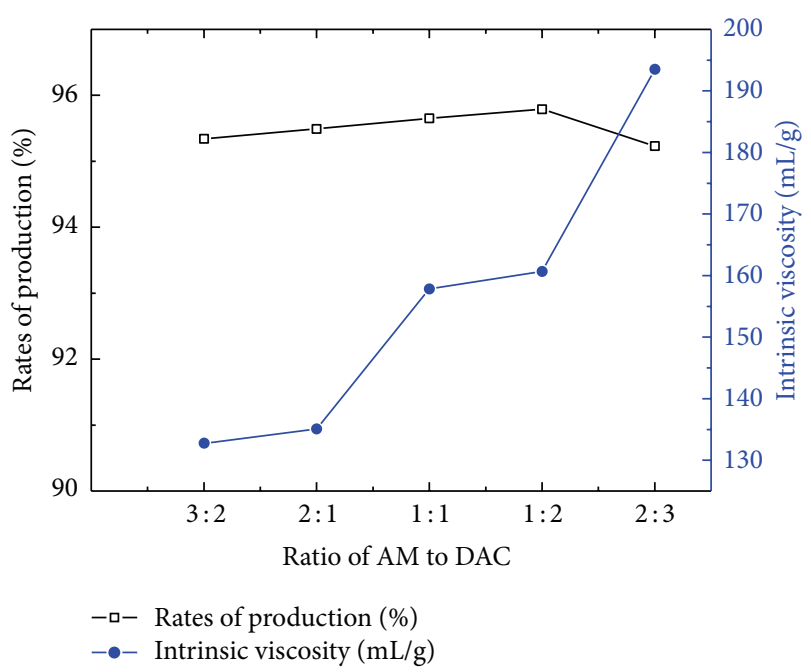

FIGURE 14: Effects of ratio of monomers on intrinsic viscosity and rates of production.

Figure 14 illustrates the relationship between the ratio of $\mathrm{AM}$ and DAC with intrinsic viscosity of branched cationic polyacrylamide. From Figure 14, it can be seen that the intrinsic viscosity of production increase with the increase of the ratio of AM and DAC. Because the molecular DAC contains strong polar groups, the copolymer obtained becomes stickier and stickier with the increase of DAC. From Figure 14, it can also be seen that the rates of production increased with the increase of the ratio of AM and DAC at first and decreased in the end.

Figures 15 and 16 are the curves of the flocculation performance branched cationic polymers obtained for sewage under different ratios of monomers. Figure 15 illustrates the efficiencies of turbidity removal, and Figure 16 demonstrates the efficiencies of COD removal. It can be seen from 


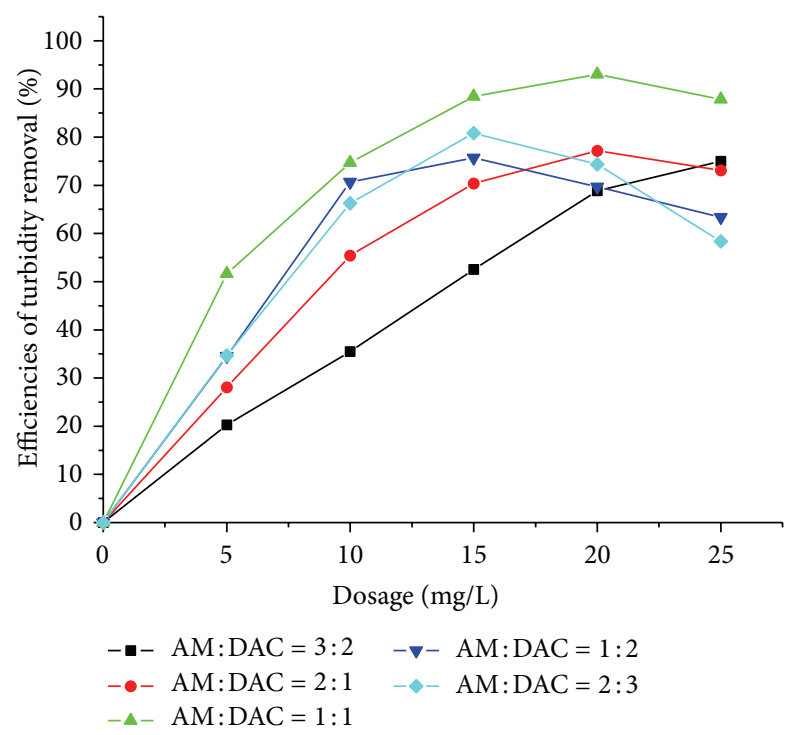

Figure 15: Effects of ratio of monomers on turbidity removal for sewage.

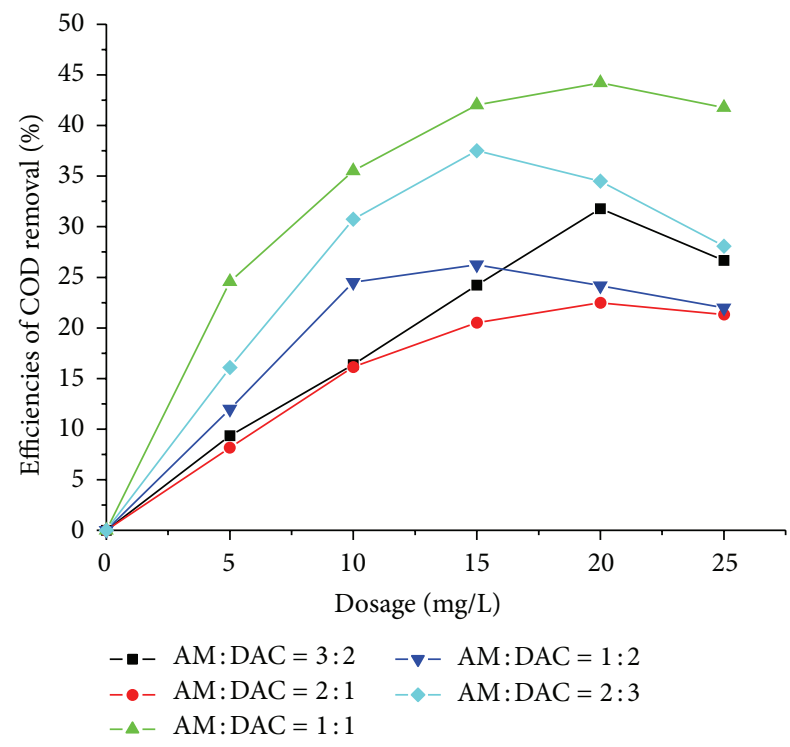

FIGURE 16: Effects of ratio of monomers on COD removal for sewage.

Figures 15 and 16 that the flocculation properties of copolymer obtained were worse with the lower ratio of DAC, and the efficiencies of turbidity and COD removal for sewage were lower too. With the increase of the ratio of DAC, the flocculation property of copolymer obtained became better. But if the ratio of DAC was too much, the polarity of copolymer was too strong, and it made separation and purification more difficult, and its flocculation properties decreased too much. The experimental demonstrated the weight ratio of AM and DAC at $1: 1$, and its flocculation property for sewage was the optimum.

3.4. Orthogonal Experiment. Orthogonal Experiment reveals the complex cause-effect relationship between design parameters and performance. A key objective of this method is to uncover how the various design parameters and environmental factors affect the ultimate performance of the product or process being designed. Orthogonal arrays are special experimental designs that require only a small number of experimental trials to help discover main factor effects [19].

The orthogonal experiment was a scientific method to study the effects of many different factors on material properties. It is used to reduce the number of experiments, based on the statistical findings. In order to determine the effects of initiator concentration, monomer concentration, reaction temperature, and the mass ratio of monomers on intrinsic viscosity and flocculation properties of the product comprehensively, an orthogonal experiment was done. Based on the single-factor experiment, the factors and levels are shown in Table 1. The results of synthesis are shown in Table 2. The results of the jar test for sewage are shown in Table 3 , and the dosage was $20 \mathrm{mg} / \mathrm{L}$ based on the single-factor experiment before.

The range analysis with intrinsic viscosity is shown in Table 4 , the range analysis of efficiencies of turbidity removal is shown in Table 5, and the range analysis of efficiencies of turbidity removal is shown in Table 6. Statistic parameters were defined as

$$
\begin{gathered}
L_{i}=\sum I_{i}, \\
K_{i}=\frac{L_{i}}{3}, \\
R=\max \left(K_{i}\right)-\min \left(K_{i}\right),
\end{gathered}
$$

where $i$ is the experimental levels, $i=1,2,3 ; I$ is experimental results, such as intrinsic viscosity, efficiencies of turbidity, or COD removal.

From Table 4, it can be seen that $R_{A}>R_{B}>R_{D}>R_{C}$. It demonstrated that the intrinsic viscosity was most affected by concentration of initiators, followed by concentration of monomers, the ratio of monomers, and reaction temperature. The optimum combination was $A_{1} B_{3} C_{3} D_{3}$. Based on the regular free radical polymerization, the concentration of initiator is the most fundamental factor that affects the properties of polymers, and concentration of initiator was much or less will influenced much the intrinsic viscosity of the polymer obtained.

From Table 5, it can be seen that $R_{D}>R_{A}>R_{C}>$ $R_{B}$. It demonstrates that the efficiency of turbidity removal of polymers for sewage was affected most by the ratio of monomers, followed by the concentration of initiators, reaction temperature, and concentration of monomers. The optimum combination was $A_{1} B_{3} C_{2} D_{1}$.

From Table 6, it can be seen that $R_{A}>R_{B}>R_{D}>$ $R_{C}$. It demonstrates that the efficiency of COD removal of polymers for sewage was affected most by the concentration of initiators, followed by the ratio of monomers, concentration of monomers, and reaction temperature. The optimum combination was $A_{2} B_{1} C_{3} D_{1}$. 
TABLE 1: Factors and levels.

\begin{tabular}{|c|c|c|c|c|}
\hline Levels & $\begin{array}{c}A \\
\text { Concentration of initiators } \\
\left(5.6 \times 10^{-4} \mathrm{mom} / \mathrm{L}\right)\end{array}$ & $\begin{array}{c}B \\
\text { Concentration of monomers (\%) }\end{array}$ & $\begin{array}{c}C \\
\text { Temperature }\left({ }^{\circ} \mathrm{C}\right)\end{array}$ & $\begin{array}{c}D \\
\text { Ratios of AM to DAC }\end{array}$ \\
\hline 1 & 5 & 25 & 45 & $2: 3$ \\
\hline 2 & 7 & 35 & 50 & $1: 1$ \\
\hline 3 & 10 & 45 & 55 & $3: 2$ \\
\hline
\end{tabular}

TABLE 2: Results of synthesis.

\begin{tabular}{|c|c|c|c|c|c|c|}
\hline \multirow{2}{*}{ No. } & \multirow{2}{*}{$\begin{array}{l}\text { Combination of } \\
\text { factors and levels }\end{array}$} & \multicolumn{4}{|c|}{ Factors } & \multirow{2}{*}{$\begin{array}{c}\text { Intrinsic viscosity } \\
(\mathrm{mL} / \mathrm{g})\end{array}$} \\
\hline & & $\begin{array}{c}\text { Concentration of } \\
\text { initiators } \\
\left(5.6 \times 10^{-4} \mathrm{mom} / \mathrm{L}\right)\end{array}$ & $\begin{array}{c}\text { Concentration of } \\
\text { monomers } \\
(\%)\end{array}$ & $\begin{array}{c}\text { Temperature } \\
\left({ }^{\circ} \mathrm{C}\right)\end{array}$ & $\begin{array}{c}\text { Ratios of AM to } \\
\text { DAC }\end{array}$ & \\
\hline 1 & $A_{1} B_{1} C_{1} D_{1}$ & 5 & 25 & 45 & $2: 3$ & 120.43 \\
\hline 2 & $A_{1} B_{2} C_{2} D_{2}$ & 5 & 35 & 50 & $1: 1$ & 221.24 \\
\hline 3 & $A_{1} B_{3} C_{3} D_{3}$ & 5 & 45 & 55 & $3: 2$ & 302.84 \\
\hline 4 & $A_{2} B_{1} C_{2} D_{3}$ & 7 & 25 & 50 & $3: 2$ & 104.19 \\
\hline 5 & $A_{2} B_{2} C_{3} D_{1}$ & 7 & 35 & 55 & $2: 3$ & 134.27 \\
\hline 6 & $A_{2} B_{3} C_{1} D_{2}$ & 7 & 45 & 45 & $1: 1$ & 186.05 \\
\hline 7 & $A_{3} B_{1} C_{3} D_{2}$ & 10 & 25 & 55 & $1: 1$ & 69.77 \\
\hline 8 & $A_{3} B_{2} C_{1} D_{3}$ & 10 & 35 & 45 & $3: 2$ & 106.58 \\
\hline 9 & $A_{3} B_{3} C_{2} D_{1}$ & 10 & 45 & 50 & $2: 3$ & 121.66 \\
\hline
\end{tabular}

TABLE 3: Results of jar test for sewage.

\begin{tabular}{lccc}
\hline No. & $\begin{array}{c}\text { Combination of } \\
\text { factors and levels }\end{array}$ & $\begin{array}{c}\text { The best rate of } \\
\text { turbidity removal } \\
(\%)\end{array}$ & $\begin{array}{c}\text { The best rate of } \\
\text { COD removal (\%) }\end{array}$ \\
\hline 1 & A1B1C1D1 & 87.31 & 45.61 \\
2 & A1B2C2D2 & 85.67 & 31.52 \\
3 & A1B3C3D3 & 86.25 & 33.33 \\
4 & A2B1C2D3 & 86.45 & 47.37 \\
5 & A2B2C3D1 & 87.67 & 57.0 \\
6 & A2B3C1D2 & 84.23 & 34.78 \\
7 & A3B1C3D2 & 80.55 & 27.17 \\
8 & A3B2C1D3 & 82.57 & 25.00 \\
9 & A3B3C2D1 & 85.84 & 30.95 \\
\hline
\end{tabular}

TABLE 4: Range analysis with intrinsic viscosity.

\begin{tabular}{lcccc}
\hline & $A$ & $B$ & $C$ & $D$ \\
\hline$L_{1}$ & 644.51 & 294.39 & 413.06 & 376.36 \\
$L_{2}$ & 424.51 & 462.09 & 447.09 & 477.06 \\
$L_{3}$ & 298.01 & 610.55 & 506.88 & 513.61 \\
$K_{1}$ & 214.84 & 98.13 & 137.69 & 125.45 \\
$K_{2}$ & 141.50 & 154.03 & 149.03 & 159.02 \\
$K_{3}$ & 99.34 & 203.52 & 168.96 & 171.20 \\
$R$ & 115.50 & 105.39 & 31.27 & 45.75 \\
\hline
\end{tabular}

Based on the comprehensiveness of the range analysis of Tables 4, 5, and 6, the factors and levels of the orthogonal experiment were optimized as shown in Table 7 [20].
TABLE 5: Range analysis with efficiencies of turbidity removal for sewage.

\begin{tabular}{lcccc}
\hline & $A$ & $B$ & $C$ & $D$ \\
\hline$L_{1}$ & 259.23 & 254.31 & 254.11 & 260.82 \\
$L_{2}$ & 258.35 & 255.91 & 257.96 & 250.45 \\
$L_{3}$ & 248.96 & 256.32 & 254.47 & 255.27 \\
$K_{1}$ & 86.41 & 84.77 & 84.70 & 86.94 \\
$K_{2}$ & 86.12 & 85.30 & 85.99 & 83.48 \\
$K_{3}$ & 82.99 & 85.44 & 84.82 & 85.09 \\
$R$ & 3.42 & 0.67 & 1.28 & 3.46 \\
\hline
\end{tabular}

TABLE 6: Range analysis with efficiencies of COD removal for sewage.

\begin{tabular}{lcccc}
\hline & $A$ & $B$ & $C$ & $D$ \\
\hline$L_{1}$ & 110.46 & 120.15 & 105.39 & 133.56 \\
$L_{2}$ & 139.15 & 113.52 & 109.84 & 93.47 \\
$L_{3}$ & 83.12 & 99.06 & 117.5 & 105.7 \\
$K_{1}$ & 36.82 & 40.05 & 35.13 & 44.52 \\
$K_{2}$ & 46.38 & 37.84 & 36.61 & 31.16 \\
$K_{3}$ & 27.71 & 33.02 & 39.17 & 35.23 \\
$R$ & 18.67 & 7.03 & 4.04 & 13.36 \\
\hline
\end{tabular}

Considering the factors affecting the primary and secondary orders, coupled with the single-factor experiment, the change rule of searching for the best levels of intrinsic viscosity and flocculation properties, the flocculation performance of the polymer was the better, the optimum condition was $A_{1} B_{3} C_{2} D_{1}$, the concentration of initiators was 
TABLE 7: Optimization of factors and levels.

\begin{tabular}{lccc}
\hline $\begin{array}{l}\text { Concentration of } \\
\text { initiators } \\
\left(5.6 \times 10^{-4} \mathrm{~mol} / \mathrm{L}\right)\end{array}$ & $\begin{array}{c}\text { Concentration } \\
\text { of monomers } \\
(\%)\end{array}$ & $\begin{array}{c}\text { Reaction } \\
\text { temperature } \\
\left({ }^{\circ} \mathrm{C}\right)\end{array}$ & $\begin{array}{c}\text { The ratio of } \\
\text { AM }: \text { DAC }\end{array}$ \\
\hline $5[1]^{*}$ & $45[2]$ & $55[4]$ & $3: 2[3]$ \\
$10[1]$ & $45[4]$ & $50[3]$ & $3: 2[2]$ \\
$5[2]$ & $45[4]$ & $50[3]$ & $2: 3[1]$ \\
$7[1]$ & $25[3]$ & $55[4]$ & $2: 3[2]$ \\
\hline
\end{tabular}

${ }^{*}$ The numbers indicate the relative effect order in the range analysis above.

$5 \times 5.6 \times 10^{-4} \mathrm{~mol} / \mathrm{L}$, the concentration of monomers was $45 \%$, the reaction temperature was $50^{\circ} \mathrm{C}$, and the weight ratio of $\mathrm{AM} / \mathrm{DAC}$ was $2: 3$.

\section{Conclusions}

A branched cationic polyacrylamide was synthesized using self-condensating vinyl copolymerization of acrylamide and DAC monomer, with $\mathrm{Cu}$ (III) as initiator. The effects of concentration of initiators and monomers, reaction temperature, and the ratio of AM to DAC on intrinsic viscosity of production were evaluated using single-factor and orthogonal experiments. Its branched structure was characterized using FTIR and $1 \mathrm{H}$ NMR spectrum. Its flocculation properties were evaluated using jar test with sewage. Its turbidity removal efficiency for sewage was $80 \%$ or higher. The COD removal efficiency for sewage was $50 \%$ or higher. The branched cationic polyacrylamide can be used as a novel flocculant in water and wastewater treatment.

\section{Acknowledgment}

This work received financial support from NWPU Basic Research Fund (JC20120249).

\section{References}

[1] American Water Works Association, Water Quality and Treatment-A Handbook of Community Water Supplies, McGraw-Hill, New York, NY, USA, 5th edition, 1999.

[2] J. Gregory, Particles in Water Properties and Processes, Taylor \& Francis, 2006.

[3] M. L. Davis, Water and Wastewater Engineering. Design Principles and Practice, McGraw-Hill, 2010.

[4] B. Tian, X. Ge, G. Pan, and Z. Luan, "Effect of nitrate or sulfate on flocculation properties of cationic polymer flocculants," Desalination, vol. 208, no. 1-3, pp. 134-145, 2007.

[5] Q. Ye, Z. Zhang, and X. Ge, "Highly efficient flocculant synthesized through the dispersion copolymerization of watersoluble monomers induced by $\gamma$-ray irradiation: synthesis and polymerization kinetics," Journal of Applied Polymer Science, vol. 89, no. 8, pp. 2108-2115, 2003.

[6] J. Bratby, Coagulation and Flocculation in Water and Wastewater Treatment, IWA Publishing, London, UK, 2nd edition, 2006.

[7] B. Bolto and J. Gregory, "Organic polyelectrolytes in water treatment," Water Research, vol. 41, no. 11, pp. 2301-2324, 2007.
[8] J. W. Qian, X. J. Xiang, W. Y. Yang et al., "Flocculation performance of different polyacrylamide and the relation between optimal dose and critical concentration," European Polymer Journal, vol. 40, pp. 1699-1704, 2004.

[9] D. J. Read, D. Auhl, C. Das, J. den Doelder et al., "Linking models of polymerization and dynamics to predict branched polymer structure and flow," Science, vol. 333, pp. 1871-1875, 2011.

[10] D. Y. Yan, C. Gao, and H. Frey, Hyperbranched Polymers: Synthesis, Properties, and Applications, John Wiley \& Sons, Hoboken, NJ, USA, 2011.

[11] E. Antunes, F. A. P. Garcia, P. Ferreira et al., "Use of new branched cationic polyacrylamides to improve retention and drainage in papermaking," Industrial \& Engineering Chemistry Research, vol. 47, pp. 9370-9375, 2008.

[12] L. J. Hobson and W. J. Feast, "Poly(amidoamine) hyperbranched systems: synthesis, structure and characterization," Polymer, vol. 40, no. 5, pp. 1279-1297, 1999.

[13] Y. H. Liu, X. R. Song, H. M. Shi, and L. L. Xu, "Study on the kinetics of polymerization by new initiation systems copper $\mathrm{Cu}$ (III) complex Ion (I) -polymerization of acrylamide initiated by self-reduction," Chemical Journal of Chinese Universities, vol. 11, pp. 328-330, 1990.

[14] X. Zhang, W. Liu, Y. Chen, A. Gong, C. Chen, and F. Xi, "Self-condensing vinyl polymerization of acrylamide," Polymer Bulletin, vol. 43, no. 1, pp. 29-34, 1999.

[15] W. M. Sun, G. C. Zhang, H. L. Li, D. D. Li et al., "Synthesis, characterization, and flocculating properties of branched polyacrylamides," Advanced Materials Research, vol. 476-478, pp. 2311-2316, 2012.

[16] P. K. Jaiswal and K. L. Yadava, "Determination of sugars and organic acids with periodato complex of Cu(III)," Indian Journal of Chemistry, vol. 11, pp. 837-838, 1973.

[17] Ministry of Environmental Protection of the People's Republic of China, Monitoring and Analysis Method of Water and Waste Water, Environmental Science Press, Beijing, China, 4th edition, 2002.

[18] H. Mori, A. Walther, X. André, M. G. Lanzendörfer, and A. H. E. Müller, "Synthesis of highly branched cationic polyelectrolytes via self-condensing atom transfer radical copolymerization with 2-(diethylamino)ethyl methacrylate," Macromolecules, vol. 37, no. 6, pp. 2054-2066, 2004.

[19] T. Yuan, Q.-F. Luo, J.-Y. Hu et al., "A Study on Arsenic Removal from Household Drinking Water," Journal of Environmental Science and Health, vol. 38, pp. 1731-1744, 2003.

[20] R. Shuxia, Synthesis and Application of Star Cationic Polyacrylamide, Kunming University of Science and Technology, 2007. 

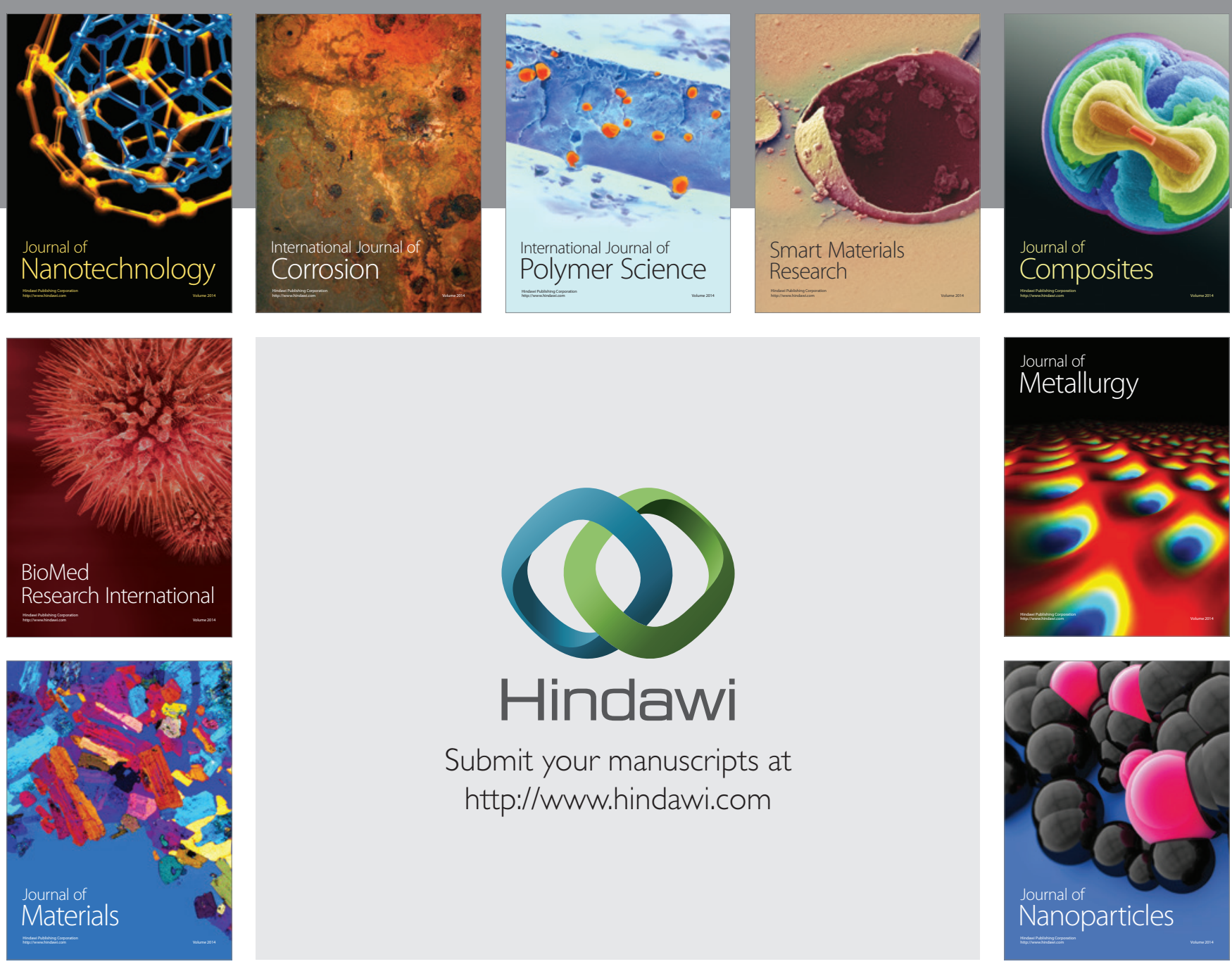

Submit your manuscripts at http://www.hindawi.com
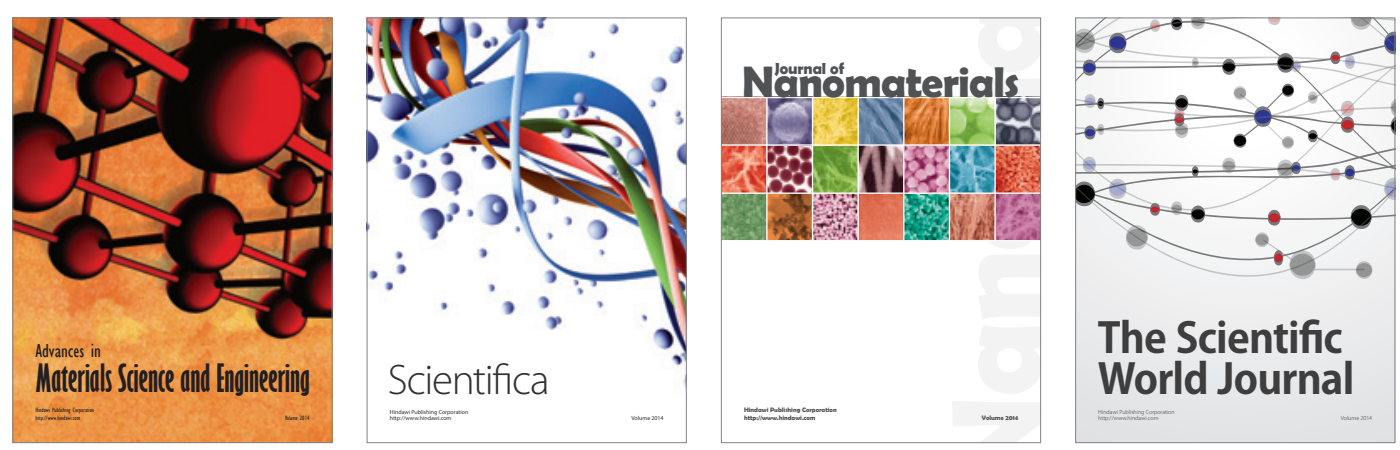

\section{The Scientific World Journal}
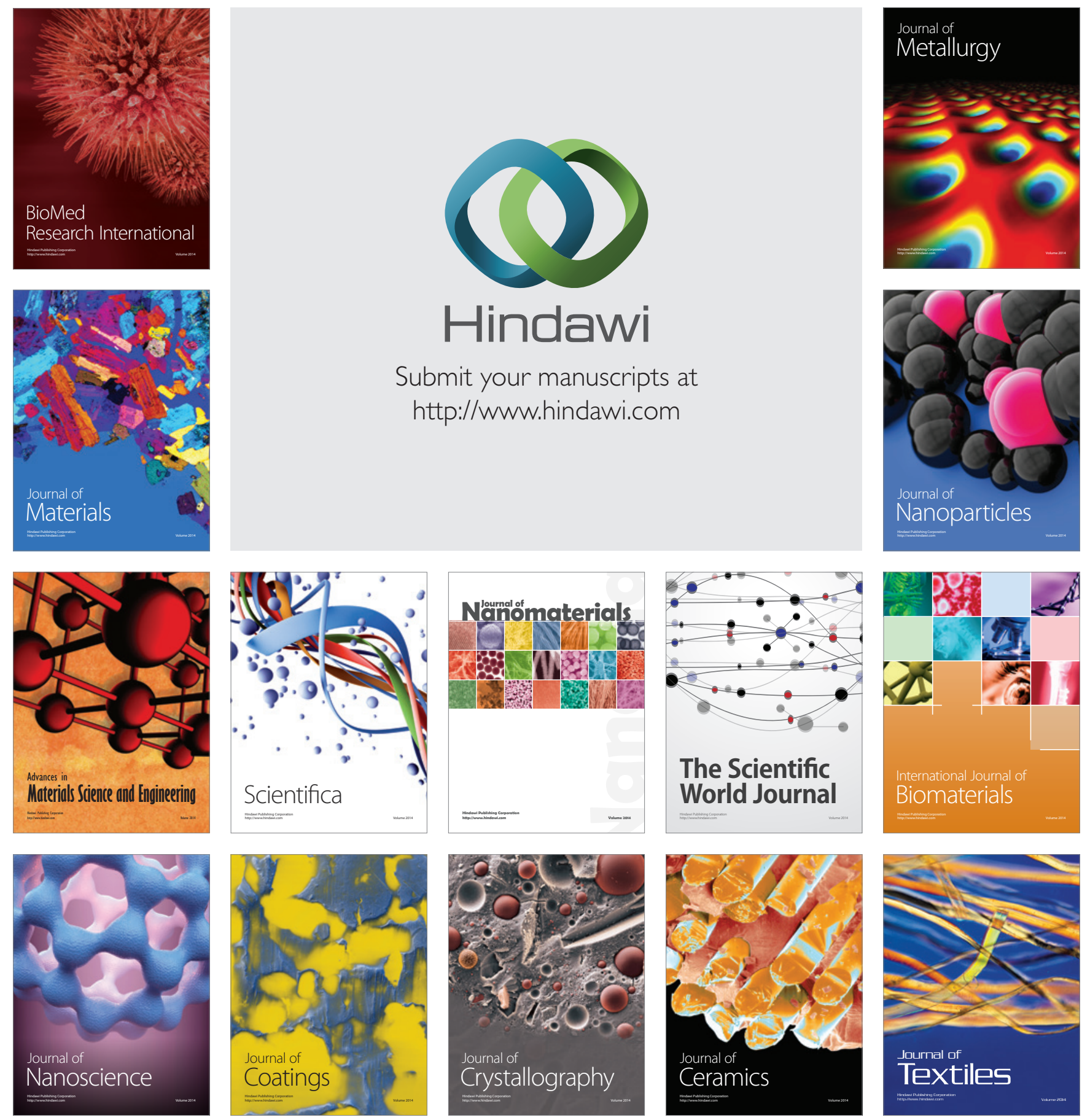